Natalia VIERHOGLIADOVA ${ }^{1}$ Ruslan SZOSTAK ${ }^{2}$

\title{
СТРАТЕГИИ РАЗВИТИЯ УКРАИНСКИХ РОЗНИЧНЫХ КОМПАНИЙ В УСЛОВИЯХ ГЛОБАЛИЗАЦИИ
}

В статье представлен анализ деятельности торговых предприятий в Украине и оценка возможных сценариев применения стратегий конкуренции. Исследовано поведение фирм в условиях международной конкуренции.

Ключевые слова: розничная продажа, структура продаж, лидеры рынка, модели поведения фирм.

\section{STRATEGIE ROZWOJU UKRAIŃSKICH FIRM HAN- DLOWYCH W WARUNKACH GLOBALIZACJI}

W artykule przedstawiono analizę działalności firm handlowych na Ukrainie oraz ocenę możliwych scenariuszy strategii konkurencji. Zbadano zachowanie firm w warunkach konkurencji międzynarodowej.

Kluczowe słowa: sprzedaż detaliczna, struktura sprzedaży, liderzy rynku, modele zachowania firm.

Украина - страна со значительным потенциалом развития сферы розничных продаж. Тому есть простое очевидное объяснение - относительно низкий уровень розничных продаж на душу населения. - см. таблицу 1.

Таблица 1. Относительный уровень продаж по странам

\begin{tabular}{|l|l|c|c|}
\hline Страна & $\begin{array}{c}\text { Население, } \\
\text { млн. чел. }\end{array}$ & $\begin{array}{c}\text { Объем розничных } \\
\text { продажс в год на 1 } \\
\text { жителя, евро. }\end{array}$ \\
\hline 1. & Россия & 172 & 1860 \\
\hline 2. & Германия & 83 & 4048 \\
\hline 3. & Франция & 62 & 5774 \\
\hline 4. & Великобритания & 61 & 6426 \\
\hline
\end{tabular}

\footnotetext{
${ }^{1}$ Natalia Vierhogliadova - profesor, dr hab., Kierownik Katedry Ekonomii i Zarządzania Przydnieprowskiej Państwowej Akademii Budownictwa i Architektury, Dniepropietrowsk, Ukraina;

${ }^{2}$ Ruslan Szostak, doktorant Katedry Ekonomii i Zarządzania Przydnieprowskiej Państwowej Akademii Budownictwa i Architektury, Dniepropietrowsk, Ukraina.
} 


\begin{tabular}{|l|l|c|c|}
\hline $\mathbf{5 .}$ & Украина & $\mathbf{4 6}$ & $\mathbf{5 0 0}$ \\
\hline 6. & Польша & 38 & 2552 \\
\hline 7. & Чехия & 10 & 2900 \\
\hline 8. & Венгрия & 10 & 2900 \\
\hline 9. & Словакия & 6 & 2166 \\
\hline
\end{tabular}

Поэтому неудивительно, что в условиях увеличивающейся глобализации украинский рынок становиться весьма привлекательным для западных компаний, которые столкнулись с насыщением рынка у себя на родине и ищут возможностей для экспансии.

В связи с этим возникла необходимость провести исследование стратегических альтернатив развития, которые могут использовать украинские компании розничной торговли в условиях вторжения на рынок западных компаний.

Все исследование мы разделили на 3 логически связанных этапа. Сначала мы провели анализ существующего состояния отрасли в Украине. Потом исследовали возможные стратегические альтернативы для предприятий отрасли в условиях надвигающейся глобальной конкуренции. И в третей части - обрисовали основные будущие тенденции развития отрасли розничных продаж.

\section{1. АНАЛИЗ РЫНКА РОЗНИЧНОЙ ТОРГОВЛИ В УКРАИНЕ}

Ситуация с относительно низким уровнем продаж естественно приводит к тому, что в настоящее время украинская торговля показывает высокие темпы роста по сравнению с государствами - соседями.

Среднегодовые темпы роста розничных продаж за период с 2002 по 2008 год в Украине составили 26\%. За аналогичный период в России данный показатель составил $17 \%$, в Польше и Румынии - 15\%, Болгарии - $11 \%$, Чехии $-10 \%$, а Германии - всего $1 \%$.

Если провести анализ структуры продаж в Украине, то можно отметить особенность, которая заключается в низкой доле продаж (по отношению к развитым странам) продаж через розничные сети. В 2009 году через них было реализовано лишь 44\% всех продаж. При общем объеме розничных продаж в 17,3 млрд. евро.

Анализ структуры продаж различных форматов магазинов показывает, что довольно низкая доля у магазинов недорогих форматов, таких как гипермаркет и дискаунтер. См. таблицу 2.

Таблица 2. Структура продаж по форматам магазинов

\begin{tabular}{|l|l|c|}
\hline & \multicolumn{1}{|c|}{ Формат } & Доля, $\%$ \\
\hline 1. & Супермаркет & 37 \\
\hline 2. & Сash\&Сarry & 16 \\
\hline $\mathbf{3 .}$ & Гипермаркет & $\mathbf{1 5}$ \\
\hline $\mathbf{4 .}$ & Дискаунтер & $\mathbf{1 4}$ \\
\hline 5. & Магазин у дома & 13 \\
\hline 6. & Прочие & 5 \\
\hline
\end{tabular}


Если сравнить ситуацию в розничной торговли в Украине и Польше, то можно отметить ситуацию отсроченного во времени повтора событий.

Экспансия иностранных розничных компаний в Польшу достигла пика в 19952001 гг., а затем почти остановилась. Большая часть ведущих розничных компаний уже присутствует на рынке, конкуренция высока.

Первые иностранные розничные компании вышли на рынок Украины в 1999 г. Экспансия ускорилась в 2007 г., и ее пик ожидается в ближайшие несколько лет ввиду планов многих ведущих розничных компаний по открытию магазинов в Украине.

В настоящее время в Украине можно выделить следующих основных игроков на рынке розничных продаж. Безусловным лидером по количеству магазинов среди торговых сетей Украины, является сеть дискаунтеров «АТБ-маркет», которая на конец 2009 года насчитывала 372 магазина и охватывала 14 регионов. Только в декабре компания поставила новый рекорд по открытию новых торговых точек 19 магазинов в месяц. В целом за год «АТБ-маркет» открыл 83 магазина. Товарооборот «АТБ» за 2009 год составил более 8,9 млрд. грн.

Вторую позицию рейтинга также уверенно сохраняет Fozzy Group (TM Fozzy $\mathrm{C} \& \mathrm{C}$, «Сільпо», «Фора»), которая за 2009 года расширилась на 16 магазинов (до 298) и покрывает 24 региона Украины.

Закрытие некоторых торговых точек не помешало «Фуршету» занять третью позицию рейтинга. При общем уменьшении количества площадок (99 магазинов в 2009 году против 102 в 2008 году), за 2009 год «Фуршет» открыл 5 новых магазинов. Четвертый в рейтинге - «ПАККО-холдинг» («Вопак», «Пакко»), проблемы с кредитными ресурсами которого значительно тормозят развитие компании: за год компания открыла три новых магазина, а два закрыла.

В пятерку крупнейших компаний Украины в 2009 году ворвалась компания «Евротек». За последние два года компания заключила успешные сделки М\&А. Это позволило только за 2009 год открыть 74 новых магазина и объединить в одну компанию 5 розничных брендов - «Фреш», «Арсен», «Квартал», «Союз», FreshMarket.

Рекорды по открытию новых магазинов в 2009 году ставили в основном региональные сети дискаунтеров. Прорыв совершила компания «Украинский ритейл» («Брусниця»), которая входит в состав «СКМ», подконтрольной Ринату Ахметову. За 2009 год сеть пополнилась 32 новыми магазинами, в результате торговая сеть выросла до 68 точек. Благодаря этому компания взлетела в рейтинге за год с девятого на шестое место, потеснив «ЭКО» (ЭКО-маркет), Volwest Group («Наш Край», «Наш Край-экспресс») и «Квиза Трейд» («Велика Кишеня», «Просто маркет»).

В лидерах по количеству открытых в 2009 году магазинов есть и новички рынка: Rainford - 29 новых магазинов и «Торговая сеть №1» («Добрый купец») - 28 точек. При этом сеть «Добрый купец» начала работу только в 2009 году. Также новичком-2009 в кризисный год стал литовский оператор «ЦЕНТР-Т», открывший 11 магазинов под брендом Novus.

Одновременно с этим из списка исчезли «Большая ложка», «Вестер», «О’КЕЙ», «МД Ритейл», «Тристан», «Ален», «Оливье». Именно за счет поглощения этих сетей нынешним лидерам открытий удалось расширить свои сети. 
Таким образом развиваться в 2009 году удавалось в основном мелким региональным сетям. Они не обременены кредитами в отличие от национальных сетей и развивались за счет собственных средств.

27 розничных торговых сетей (из 50) сумели в кризисных условиях увеличить количество магазинов, 9 операторов - сократили.

Таблица 3. Основные компании на рынке розничных продаж в Украине

\begin{tabular}{|c|c|c|c|c|}
\hline Сети & $\begin{array}{c}\text { Количество } \\
\text { торговых точек, } \\
\text { конец } 2009\end{array}$ & \begin{tabular}{|c|} 
Количество \\
торговых \\
точек, \\
конец 2008
\end{tabular} & $\begin{array}{c}\text { Количество } \\
\text { открытых в } \\
2009 \\
\text { торговых } \\
\text { точек }\end{array}$ & $\begin{array}{c}\text { Количество } \\
\text { областей } \\
\text { покрытия }\end{array}$ \\
\hline АТБ & 372 & 292 & 83 & 14 \\
\hline $\begin{array}{l}\text { Сільпо, Фора, Фоззі, } \\
\text { Буми-маркет }\end{array}$ & 298 & 283 & 16 & 24 \\
\hline Фуршет & 99 & 102 & 5 & 21 \\
\hline Вопак, Пакко & 86 & 85 & 3 & 10 \\
\hline $\begin{array}{l}\text { Фреш, Арсен, } \\
\text { Квартал, Союз, } \\
\text { Fresh-Market } \\
\end{array}$ & 74 & 9 & 74 & 11 \\
\hline Брусниця & 68 & 38 & 32 & 5 \\
\hline ЕКО-маркет & 67 & 65 & 9 & 14 \\
\hline $\begin{array}{l}\text { Наш Край, Наш } \\
\text { Край-экспресс }\end{array}$ & 55 & 58 & 22 & 13 \\
\hline $\begin{array}{l}\text { Велика Кишеня, } \\
\text { Просто маркет }\end{array}$ & 48 & 52 & 1 & 18 \\
\hline Рукавичка & 43 & 30 & 13 & 1 \\
\hline Rainford & 43 & 14 & 29 & 4 \\
\hline Плюс & 33 & 28 & 5 & 2 \\
\hline Таврия-В, Космос & 32 & 32 & 0 & 4 \\
\hline SPAR & 29 & 32 & 7 & 7 \\
\hline Добрый купец & 28 & 0 & 28 & 6 \\
\hline Metro & 25 & 23 & 2 & 15 \\
\hline Абсолют (Луганск) & 25 & 22 & 4 & 3 \\
\hline Амстор & 24 & 23 & 1 & 5 \\
\hline Барвінок & 24 & 23 & 1 & 3 \\
\hline Эконом-плюс & 24 & 21 & 3 & 2 \\
\hline Копійка & 22 & 22 & 2 & 2 \\
\hline Колібріс, Наш & 21 & 21 & 1 & 6 \\
\hline Фаворит & 19 & 30 & 0 & 1 \\
\hline Billa & 19 & 14 & 5 & 10 \\
\hline $\begin{array}{l}\text { Торговий світ, } \\
\text { Ровекс }\end{array}$ & 19 & 18 & 2 & 3 \\
\hline Полагросервис & 17 & 14 & 3 & 1 \\
\hline Економ, Бакалія & 16 & 16 & 0 & 2 \\
\hline
\end{tabular}




\begin{tabular}{|c|c|c|c|c|}
\hline Сети & $\begin{array}{c}\text { Количество } \\
\text { торговых точек, } \\
\text { конец } 2009\end{array}$ & $\mid \begin{array}{c}\text { Количество } \\
\text { торговых } \\
\text { точек, } \\
\text { конец } 2008\end{array}$ & $\begin{array}{c}\text { Количество } \\
\text { открытых в } \\
2009 \\
\text { торговых } \\
\text { точек } \\
\end{array}$ & $\begin{array}{c}\text { Количество } \\
\text { областей } \\
\text { покрытия }\end{array}$ \\
\hline Обжора (Одесса) & 15 & 13 & 2 & 1 \\
\hline Виртус & 14 & 12 & 2 & 2 \\
\hline Mapc & 14 & 14 & 0 & 2 \\
\hline $\begin{array}{l}\text { Обжора (Донецк), } \\
\text { Gourmet }\end{array}$ & 14 & 12 & 2 & 1 \\
\hline Абсолют (Черкассы) & 14 & 15 & 0 & 1 \\
\hline 555 & 13 & 13 & 2 & 2 \\
\hline $\begin{array}{l}\text { Корона, Грош, К- } \\
\text { Маркет } \\
\end{array}$ & 12 & 12 & 1 & 1 \\
\hline Седам & 12 & 13 & 0 & 1 \\
\hline Дигма & 11 & 9 & 2 & 1 \\
\hline Novus & 11 & 0 & 11 & 3 \\
\hline БиМаркет & 11 & 9 & 3 & 1 \\
\hline Аликон-маркет & 11 & 11 & 1 & 1 \\
\hline Таргет & 10 & 10 & 0 & 1 \\
\hline Колос & 10 & 6 & 4 & 1 \\
\hline Шара & 9 & 9 & 0 & 1 \\
\hline Пан-маркет & 9 & 0 & 9 & 1 \\
\hline Островок & 8 & 12 & 0 & 1 \\
\hline Varus & 8 & 33 & 2 & 3 \\
\hline Капи & 8 & 8 & 0 & 1 \\
\hline Оскар & 8 & 6 & 2 & 1 \\
\hline Арбат & 8 & 8 & 0 & 1 \\
\hline ЮСИ & 8 & 8 & 0 & 2 \\
\hline Ярославна & 8 & 6 & 2 & 1 \\
\hline
\end{tabular}

\section{2. АНАЛИЗ ВОЗМОЖНЫХ МОДЕЛЕЙ ПОВЕДЕНИЯ ИГРОКОВ НА РЫНКЕ РОЗНИЧНЫХ ПРОДАЖ}

В условиях угрозы вторжения на украинский рынок глобальных сетевых операторов отечественным операторам приходится интенсивно мобилизовать ресурсы и вырабатывать новые стратегии развития. При этом они демонстрируют высокие способности к адаптации, заимствуя организационные формы и технологии продаж у глобальных ритейлеров.

Развитие хозяйственных организаций в обычных условиях характеризуется достаточно высокой степенью инерционности. Но возникают ситуации, когда деловые стратегии участников рынка кардинально меняются. Чаще всего такая ломка обусловлена внешними факторами. Это могут быть общий экономический кризис или резкое изменение государством правил игры в определенном секторе. Но существует еще один внешний фактор, приводящий к радикальным и быстрым изменениям без всяких реформ или, наоборот, без провала реформаторов. Он связан 
с появлением на данном рынке новых серьезных конкурентов. Именно эта ситуация является предметом нашего исследования.

Для анализа рынок может быть представлен в качестве организационного поля (organizational field), где взаимодействуют разные типы компаний, производящих аналогичные или смежные продукты и услуги, а также компании, представляющие разные звенья в единой цепи поставок. Каждая из компаний занимает определенную рыночную нишу, в которой воспроизводятся относительно устойчивые связи компании данного типа с определенными группами поставщиков и покупателей. Эти ниши выстраиваются относительно рыночных ниш других компаний, сегментируются в зависимости от соотношения объема, цены и качества производимого продукта и образуют структуру данного организационного поля [Уайт, 2002; White, 2002].

Поведение участников рынка в организационном поле во многом определяется их деловой стратегией, под которой мы понимаем устойчивый и осмысленный выбор способов использования ограниченных ресурсов для реализации относительно долгосрочных интересов. Ключевые элементы деловой стратегии приведены на рисунке 1.

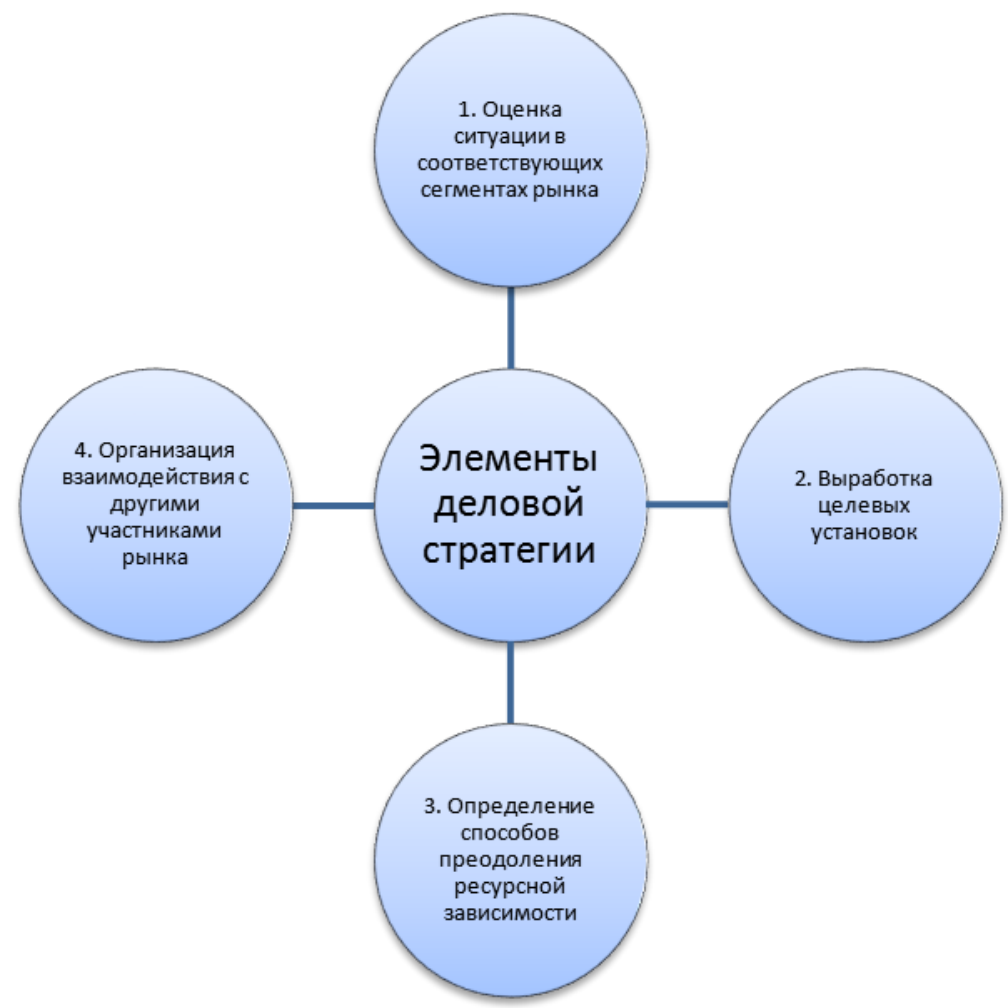

Рис. 1. Ключевые элементы деловой стратегии Рассмотрим каждый из них подробнее. 
Оценка ситуации в соответствующих сегментах рынка. При реализации деловых стратегий участники рынка пытаются установить контроль над ситуацией и действиями контрагентов, для того чтобы уменьшить неопределенность внешней среды и повысить эффективность использования ресурсов.

Существуют следующие формы контроля:

- интеграция;

- контракты;

- сетевые отношения;

- кооперация.

Формы взаимодействия участников рынка в зависимости от характера производимых продуктов и услуг и их места в цепях поставок (supply chains) подразделяются на горизонтальную форму, когда взаимодействие осуществляется между прямыми конкурентами или операторами, представляющими аналогичные звенья в разных цепях поставок (например, между магазинами смешанного формата, торгующими продовольственными и непродовольственными товарами), и вертикальную форму. Последняя возникает в процессе взаимодействия с другими участниками рынка, работающими в смежных звеньях единой цепи поставок (например, с поставщиками данной фирмы или потребителями ее продукции). Заметим, что вертикальное взаимодействие предусматривает наличие трансакций между контрагентами, в то время как при горизонтальном взаимодействии такие трансакции, как правило, отсутствуют.

В результате совмещения двух простейших классификаций мы получаем четыре способа установления контроля над действиями других участников рынка:

- горизонтальную интеграцию, связанную с концентрацией основной деятельности посредством слияния и поглощения конкурентов или диверсификацией активов через присоединение производителей других продуктов и услуг;

- вертикальную интеграцию, реализуемую посредством слияния и поглощения предприятий, располагающихся в смежных звеньях единой технологической цепи поставок, в результате чего рыночные трансакции превращаются во внутрифирменные трансакции;

- горизонтальную кооперацию, выражающуюся в заключении стратегических альянсов для реализации совместных проектов (коммерческих или политических) между прямыми конкурентами или производителями смежных продуктов без утраты их автономии с точки зрения прав собственности;

- вертикальную кооперацию, возникающую при установлении устойчивых связей с производителями, поставщиками или потребителями продукции данной фирмы без потери ими независимого организационного статуса.

Выработка целевых установок. Второй элемент деловых стратегий и их содержательное ядро образуют целевые установки участников рынка, которые могут быть разделены на конечные и инструментальные цели. Конечные цели руководителей ведущих украинских компаний в начале 2000-х гг. расходились до диаметрально противоположных. Те, кто придерживался пессимистической концепции, ориентировались на продажу бизнеса ведущим западным компаниям. Они говорили, что «бизнес есть бизнес» и, если поступит предложение, «от которого нельзя отказаться», придется продавать. Те же, кто смотрел в будущее с относительным оптимизмом, думали о расширении и удержании собственной 
ниши. Но, несмотря на противоположность конечных установок, содержание деловых стратегий в части инструментальных целей в обоих случаях оказалось весьма сходным. Чтобы выгодно «продаться» (а отдавать тяжелым трудом созданное дело за копейки мало кому захочется), приходится идти путем, которым следуют компании, заботящиеся об укреплении своих позиций в долгосрочной перспективе, а именно: увеличивать масштабы, осваивать новые технологии, достигать большей прозрачности, продвигать собственные брэнды, т. е. становиться во всех отношениях более видимыми и заметными на рынке. По существу, в инструментальной плоскости мы имеем одну и ту же деловую стратегию, которая в результате может привести и к продаже, и к сохранению компании - в зависимости от сложившейся обстановки и наличия выгодных предложений. Главное для компании - ее развитие, а затем уже можно поступать в соответствии с ситуацией. Такова схема стратегического действия с открытым результатом в противовес модельному действию, ориентирующемуся на изначально заданный итоговый результат.

Преодоление ресурсной зависимости. Рассматривая целевые установки ведущих украинских компаний, мы вплотную подошли к третьему элементу деловой стратегии - преодолению ресурсной зависимости. В данной статье ввиду ограниченности объема текста, мы остановимся лишь на вопросе об источниках финанcoвblx ресурсов для развития компаний, хотя, мобилизуя другие виды ресурсов, компании также сталкиваются сегодня с множеством проблем.

Вопрос о финансовых ресурсах в условиях быстрого экстенсивного развития стоит чрезвычайно остро. И здесь также происходят серьезные сдвиги в деловых стратегиях. В начале 2000-х гг. сетевые компании вынуждены были развиваться преимущественно за счет реинвестирования собственной прибыли. Фондовый рынок был слишком слаб, а банковские кредиты предоставлялись на не слишком выгодных условиях (жалобы на дискриминационную политику банков — высокие ставки процентов, жесткую залоговую политику - были обычным явлением). Хорошо, если за плечами компании стоял мощный стратегический инвестор. Но таким преимуществом могли похвастаться далеко не все. А начавшееся в эти годы давление, приводящее к отказу от «серых» и «черных» схем налоговой оптимизации, и общая тенденция к снижению средней торговой наценки и уровня рентабельности еще более сокращали внутренние источники финансовых ресурсов для развития.

К середине первого десятилетия XXI в. ведущие розничные компании серьезно выросли и стали куда более привлекательными объектами для финансовых и банковских институтов. Они уже не испытывают затруднений в получении банковских кредитов и способны брать их не под 15, а под 6-7\% годовых. Но на повестке дня стоит переход от кредитной политики, связанной с обеспечением операционных нужд, к инвестиционной политике, сопряженной с управлением стоимостью компании.

Для реализации этих целей необходимы стратегические инвесторы. И все же дефицит «длинных» денег сохраняется, и здесь украинские участники рынка явно уступают по инвестиционным возможностям западным гигантам.

Постепенно компании дозрели и до привлечения портфельных инвестиций на открытом рынке, значение которых, по всей видимости, будет возрастать. 
Организация взаимодействия с другими участниками рынка. Расширение бизнеса, помимо так называемого органического роста в виде создания новых собственных торговых объектов, может осуществляться как минимум в трех формах:

- слияний и поглощений (формы горизонтальной интеграции);

- франчайзинга (промежуточной формы между горизонтальной интеграцией и кооперацией);

- стратегических альянсов (формы горизонтальной кооперации).

Если говорить о продвижении товара, будь то построение системы логистики или внешнеэкономическая деятельность, связанная с импортом товаров, то украинские компании пока явно предпочитают использовать более интегрированный вариант организации цепи поставок в рамках одной бизнесгруппы и действовать через аффилированные структуры. К аутсорсингу, в отличие от западных операторов, как правило, относятся осторожно, хотя первые примеры привлечения логистических операторов уже имеются. Считается, что в Украине пока нет достаточно сильных логистических операторов, что их услуги относительно дороги, а степень надежности не столь велика. Эта ситуация в будущем, скорее всего, будет меняться по мере вхождения на украинский рынок западных логистических компаний и повышения прозрачности управленческих схем отечественных ритейлеров.

Самым серьезным образом трансформируются механизмы вертикальной кооперации между фирмами, располагающимися в смежных звеньях цепей поставок. Здесь полным ходом развивается процесс, названный (возможно, не совсем удачно) построением цепи поставок, регулируемой покупателем (buyer-driven commodity chains), где под покупателем понимаются именно розничные компании. Рост экономического веса и значимости ритейлеров в вертикальной цепи поставок приводит к тому, что они все больше контролируют поведение других звеньев этой цепи. Ведущие розничные компании начинают менять правила обмена в нужном для себя направлении.

Первыми тяжелые последствия новой конкурентной ситуации ощутили дистрибьюторы. Теперь их ожидает либо полное вытеснение, либо субординация - подчинение интересам ритейлеров. Вытеснение посредников происходит посредством установления прямых связей с производителями, что обеспечивает выигрыш в размере 5-15\% розничной цены. Те же дистрибьюторы, которые в результате отбора остаются в цепи поставок, вынуждены удовлетворять все более жестким запросам розничных сетей. Это могут быть требования максимальных скидок, отсрочек платежей, строгого соблюдения графика поставок под угрозой штрафов или прекращения работы. И поставщики вынуждены идти на эти условия, ибо розничные сети обеспечивают им гарантированные, постоянные и крупные заказы.

Особым способом субординации производителей розничными сетями является использование собственных торговых марок (СТM) (private labels). У западных компаний их доля в обороте составляет десятки процентов, у украинских речь пока идет о нескольких процентах, но такая практика становится все более популярной, и, несомненно, доля СТМ будет возрастать. Собственные торговые марки не только позволяют снижать издержки примерно на 20-30\% по сравнению с закупкой чужих брэндов, но и помогают продвигать брэнд розничной компании и становятся 
инструментом подчинения производителей, которые утрачивают собственное имя, превращаясь в технологический придаток, лишенный символического капитала. Символические ресурсы вместе с приносимым доходом экспроприируются розничными компаниями, расположившимися у ворот, открывающих доступ к конечному потребителю.

\section{3. ВЫВОДЫ}

Украинская розничная торговля имеет высокий потенциал для развития. Потребление продуктов населением Украины в рознице значительно отстает от показателей развитых стран и стран - соседей. В такой ситуации рынок розничных продаж в скором времени ждет период интенсивной конкуренции. Конкуренции как между отечественными компаниями, так и с зарубежными торговыми сетями, которые уже сейчас начинают экспансию в Украину.

Существует базовый набор стратегий поведения игроков на рынке розничных продаж. Каждая из таких стратегий имеет свои преимущества и ограничения при использовании. В зависимости от ситуации игроки рынка будут выбирать одну или несколько базовых стратегий.

Сейчас сложилась противоречивая ситуация с тенденциями развития конкурентной ситуации на украинском рынке розничных продаж. С одной стороны экономический кризис и ухудшение макроэкономический показателей Украины снизили привлекательность данного рынка. С другой - заметно снизились барьеры для входа на рынок, чем могут воспользоваться крупные зарубежные игроки отрасли.

\section{ЛИТЕРАТУРА}

1. Берман Б., Эванс Дж. Розничная торговля. Стратегический подход, М.: Вильямс, 2008

2. Леви М., Вейтц Б. Основы розничной торговли, СПб.:Питер, 1999

3. Кент Т., Омар О. Розничная торговля, М.: Юнити-Дана, 2007

4. Радаев В.В. Захват российских территорий: новая конкурентная ситуация в розничной торговле, М.: Издательский дом ГУ-ВШЭ, 2007

5. Радаев В.В., Котельникова 3.В., Маркин М.Е. Развитие российского ритейла: меры государственного регулирования и их последствия, М.: Изд. дом ГУ-ВШЭ, 2009

6. Экономическая борьба и социальные связи: структура конкурентных отношений в новом российском ритейле Радаев В.В. // Экономическая социология, 2009. Т. 10. № 1. С. 19-56

\section{UKRAINIAN DEVELOPMENT STRATEGIES OF TRADING COMPANIES IN GLOBALISATION}

The activity of trading companies in Ukraine is analyzed in the article. The analysis of possible scenarios of competition strategies is conducted. It was surveyed how companies manage in the conditions of international competition.

Key words: retail, sales structure, market leaders, behavior of firms.

DOI: 10.7862/rz.2012.zim.11 